\title{
When Adaptation is NOT the Option: Does the ERC Attenuate When Firms Are Less Likely to Use the Adaptation Option?
}

\author{
Mitchell Oler \\ Pamplin College of Business, Department of Accounting and Information Systems \\ Virginia Polytechnic Institute and State University \\ 3007 Pamplin Hall, Blacksburg, VA 24061, USA
}

Tel: 1-540-231-0764Ｆax: 1-540-231-2511Ｅ-mail: moler@vt.edu

Received: October 8, 2012

Accepted: October 17, 2012

Online Published: November 5, 2012

doi:10.5430/afr.v1n2p200

URL: http://dx.doi.org/10.5430/afr.v1n2p200

Data Availability: The data used in this study are available from public sources identified in the text.

I appreciate the helpful comments and suggestions from Bryan Cloyd, Bowe Hansen, Larry Killough, and participants at workshops at Virginia Tech University.

\begin{abstract}
This paper considers whether the earnings response coefficient (ERC) changes when firms are unlikely to adapt resources to other uses. Hayn (1995) provides evidence consistent with losses having less information content than gains. Since losses are not expected to be persistent - a key determinate in the relationship between earnings and returns - market participants discount those losses when valuing the firm and instead value it based on the adaptation option, resulting in an attenuated ERC. However, when the likelihood of the adaptation option being used is low, I predict that the ERC will not attenuate since the market will still value the firm on earnings, even though they are negative. Using a book to market (BTM) ratio above one to proxy for a reduced likelihood of adaptation, I provide evidence consistent with my hypothesis. This research combines the prior literature on the adaptation option, the ERC attenuation, and the BTM ratio.
\end{abstract}

Keywords: Information content, Earnings response coefficient, Losses, Adaptation option, Book to market

\section{Introduction}

This paper considers whether the earnings response coefficient (ERC) attenuates less when the firm is unlikely to adapt resources (assets) to other uses. Based on the efficient market hypothesis, the seminal works of Ball and Brown (1968) and Beaver (1968) provide evidence consistent with stock prices reacting to accounting information. In theory, the change in stock price should equal the unexpected change in earnings (the earnings innovation) divided by the expected rate of return for that innovation. Intuitively, each earnings innovation represents a change in the earnings process for the firm, which is valued by dividing the expected annual cash flow into the rate of return - similar to an annuity.

However, early literature on that subject often finds the ERC to be well below the theoretical magnitude (see Kormendi and Lipe, 1987). This empirical finding has been the subject of several research papers and has led to a substantial stream of literature (see Lev 1989 and Kothari, 2001 for summaries of this literature). Among the common explanations, Hayn (1995) provides evidence consistent with the low ERC being related to the transitory nature of losses. Specifically, she hypothesizes that in general, firms will discontinue operating in ventures that result in losses because the firm will adapt its resources to a better use. For example, management may have a loss division that they may choose to produce a different product or to close the division and sell the assets off. In either instance, the losses from that division are not expected to persist. Because firms have this adaptation option, the value of the firm will change from a function of earnings to a function of the adaptation option when earnings are at the adaptation point.

Burgstahler and Dichev (1997, also see Berger et al., 1996) provide empirical evidence consistent with firm value 
becoming a function of the adaptation option when earnings are low, specifically when the expected discounted value from all future earnings (referred to as the recursion value) is below the book value of the assets. Figure 1 (replicated from Burgstahler and Dichev) illustrates this relationship. The horizontal line (book value) is the point where firm value is maximized by adapting resources away from the current earnings process. Thus, the value of the firm should not go below the book value of the assets (less liabilities). In spite of the theory, Oler (2011) finds that approximately 17 percent of all firm observations have a book value that exceeds market value, suggesting that the firm is not utilizing the adaptation option. This paper considers an implication of this finding - namely that if the adaptation option is not expected to be utilized, will the market continue to price the firm on the negative earnings as opposed to the adaptation option?

I investigate this question by performing a similar analysis of Hayn (1995). I first partition observations based on the sign of the earnings - negative or positive - and regress the earnings on 12 month returns. Consistent with Hayn, I find that firms with negative earnings have a much lower ERC as well as adjusted $R^{2}$ than firms with positive earnings (Note 1). Hayn interprets the lower $R^{2}$, her measure of information content, as an indication that the market does not impound the negative earnings information into prices as much as positive earnings information. I then further partition the sample on whether the book to market (BTM) ratio is greater than one, the theoretical point of adaptation. If the probability of utilizing the adaptation option is low (proxied by the BTM ratio being greater than one), then I expect that there will be an incremental difference between the ERC's, with the ERC related to firms with a high BTM ratio not attenuating as much as the ERC related to firms with a low BTM ratio. I also predict the $R^{2}$ to be higher for the high BTM sample than for the low BTM sample.

The results are consistent with my theory. Specifically, I find that observations with negative earnings, conditional on the BTM ratio being greater than one, have a positive coefficient, suggesting that the negative earnings information is impounded more into price. On the other hand, observations with a low BTM ratio have a smaller (or more negative) ERC. The $R^{2}$ for the high BTM regressions also tend to be higher. The results hold for using both levels and changes in earnings as in Hayn.

This paper contributes by examining the interaction between the adaptation option, firm value, and earnings. This is the only paper that I am aware of that incorporates the probability of resource adaptation when considering the ERC, which in turn also helps further explain the relation between price and earnings. When earnings are low, the ERC becomes largely irrelevant because the market expects that the firm will utilize the adaptation option. However, when the expectation is that the firm will not utilize the option, earnings information, even losses, is impounded into price causing a higher ERC and $R^{2}$.

\section{Background}

Researchers and practitioners have long been interested in the relation between accounting based earnings and returns. Ball and Brown (1968) first provide evidence that there is a correlation between accounting information (earnings) and stock price. Kormendi and Lipe (1987, also see Collins and Kothari, 1989) further the research by modeling the specific relation between earnings and stock price reactions, providing evidence that a change in price (returns) relative to a change in earnings is a function of the magnitude of the earnings innovation (or change), the persistence of that innovation, and the expected rate of return for the earnings process that provided that innovation. However, an empirical result from this literature suggests that the ERC is smaller relative to the expectation, only explaining part of the expected variation in returns (see Lev, 1989 and Kothari, 2001). Kothari (2001) presents five main hypotheses for the low ERS's: pricing information leading earnings (see Kothari and Sloan, 1992); inefficient capital markets, such as the earnings price drift (see Bernard and Thomas, 1990); noise in earnings (Ramakrishnan and Thomas, 1998); deficient GAAP (see Lev 1989), and transitory earnings (for example see Freeman and Tse, 1992 and Collins et al., 1994).

This last argument, transitory earnings, questions the persistence assumption. Hayn (1995) provides evidence consistent with the transitory nature of earnings affecting the magnitude of the ERC. In the normal course of business, a firm will engage in investments (or projects) that produce a future earnings stream that is, presumably, reasonably persistent. However, when an investment fails and results in negative earnings, the firm has the incentive to stop production of that investment. This implies that negative earnings will be more transitory than positive earnings.

A key assumption for Hayn's theory is that managers will stop the current earnings process when earnings are negative. Burgstahler and Dichev (1997, also see Berger et al., 1996) provide evidence consistent with Hayn's theory via the adaptation option. Specifically, that revenue producing assets have value from alternative uses, and when earnings from a current earning process are low, the firm can adapt those resources to another use (see Figure 1). In essence, the relationship between earnings and price is low because the market is valuing the firm based on the 
adaptation option price instead of the expected future earnings from the current earnings process.

However, Oler (2011, also see Danielson and Press, 2003) provides evidence consistent with firms underutilizing the asset adaptation option. Specifically, Oler shows that on average around 17 percent of observations maintain a book value that exceeds market value, the expected point of adaptation. If a firm's BTM ratio is greater than one, then I predict that negative earnings are more likely to be viewed as less transitory and result in the ERC not attenuating as much as firms with a BTM ratio greater than one. Specifically, I hypothesize that the ERC attenuates less for loss firms with a BTM ratio greater than one relative to loss firms with a BTM ratio less than one.

\section{Method}

To test whether the ERC is larger for observations with losses but are less likely to use the adaptation option, I follow a methodology similar to Hayn (1995). I first regress 12-month returns on earnings (equation 1a below) and change in earnings (equation $1 b$ ) to establish the basic relation between earnings and returns. I then add an indicator variable that is equal to one if the BTM ratio is greater than one as well as the interaction between earnings and the indicator (equations $2 \mathrm{a}$ and $2 \mathrm{~b}$ ). The equations are provided below:

$$
\begin{gathered}
R_{i t}=\alpha+\beta_{1} \frac{X_{i t}}{P_{i t-1}}+\varepsilon_{i t} \\
R_{i t}=\alpha+\beta_{1} \frac{\Delta X_{i t}}{P_{i t-1}}+\varepsilon_{i t} \\
R_{i t}=\alpha+\beta_{1} \frac{X_{i t}}{P_{i t-1}}+\beta_{2} \text { BTMIND }^{i t}+\beta_{3} \frac{X_{i t}}{P_{i t-1}} \times \text { BTMIND }^{i t}+\varepsilon_{i t} \\
R_{i t}=\alpha+\beta_{1} \frac{\Delta X_{i t}}{P_{i t-1}}++\beta_{2} \text { BTMIND }^{i t}+\beta_{3} \frac{\Delta X_{i t}}{P_{i t-1}} \times \text { BTMIND }^{i t}+\varepsilon_{i t}
\end{gathered}
$$

where: $R_{i t} \quad=12$ month buy and hold returns over the period starting in the fourth month from prior year-end and ending three months after current year-end for firm $i$ at time $t$.

$X_{i t} \quad=$ Earnings per share for firm $i$ at time $t$.

$\Delta X_{i t} \quad=$ Change in earnings per share for firm $i$ from time $t-1$ to time $t$.

$P_{i t-1} \quad=$ Price for firm $i$ at time $t-1$.

BTMIND $_{i t} \quad=$ Indicator variable equal to 1 if observation $i$ at time $t$ has a BTM ratio greater than one and 0 otherwise.

My variables are defined in a similar manner as in Hayn. Returns are raw returns over the 12-month accumulation period starting 8 months prior to fiscal year end. Earnings are defined as earnings per share before extraordinary items, scaled by lagged price. The BTM ratio is the book value of equity at fiscal year end divided by total market value measured 3 months after fiscal year end. Similar to Hayn, I remove observations in the extreme 1 percent.

In accordance with the theory that losses are presumed to be transient, I partition the sample based on earnings (positive or negative) and on BTM ratio (above or below one). A positive coefficient $\left(\beta_{3}\right)$ on the interaction between earnings and the indicator variable $(B T M I N D)$ is consistent with my hypothesis that the market believes that these losses are not as transient when the BTM ratio is greater than one.

\section{Results}

All available observations from Compustat and CRSP are used from 1962 through 2010. To help understand the differences between the sample of observations with a BTM greater than one and the general population, Table 1 provides statistics on the whole sample (left column) and on observations that have a BTM greater than one. There are a total of 166,709 observations, 44,089 of which have a BTM greater than one. The BTM greater than one sample is smaller in both total assets and sales $(\$ 4,076$ versus $\$ 2,234$ and $\$ 1,405$ versus $\$ 653$ respectively). Additionally, observations in the BTM greater than one sample tend to be less profitable and have lower returns (all variables are significantly different with $p<0.01$ - untabulated). This is similar to Oler (2011), who finds, in general, that the BTM greater than one sample tends to be less profitable, smaller in both assets and sales, and have lower returns. The 
propensity for losses is also higher within the BTM greater than one sample, with 29 percent of the observations having negative earnings relative to the whole population where it is only 24 percent.

Table 2, panels A and B, provides the main results. I begin by replicating Hayn's model by regressing returns on earnings using OLS and partition the sample between gain/ loss observations (model 1a) (Note 2). Although the $R^{2}$ 's are somewhat smaller than Hayn's (the $R^{2}$ s are $0.0,9.3$, and 16.9 for the losses, full, and profits samples respectively), they show a similar pattern with $\operatorname{ERC}\left(R^{2}\right)_{\text {losses }}<\operatorname{ERC}\left(R^{2}\right)<_{\text {full sample }}<\operatorname{ERC}\left(R^{2}\right)_{\text {profits. }}$. The ERC for the pooled sample across all observations is positive and significant $(0.58, p<0.01)$ and the adjusted $R^{2}$ is 3.8 percent (Note 3$)$. Using the changes $\left(152,482\right.$ observations) instead of levels (panel B) gives a slightly higher ERC $(0.81)$ with an $R^{2}$ of 5.6 percent (Note 4).

The positive only observation sample (125,541 observations) has a significant coefficient (2.00) and an $R^{2}$ of 9.9 percent. The negative only observation sample (40,337 observations) has a coefficient of -0.19 with an $R^{2}$ of 0.1 percent. This result is consistent with observations that have negative earnings increasing in returns, albeit at a much lower degree than observations with positive earnings. I conjecture that the negative ERC on negative earnings (resulting in positive returns) is a result of two effects. One, increasing conservatism over time (see Givoly and Hayn, 2000), causing more observations to delay the recognition of 'good news' events and the acceleration of the recognition of 'bad news' events, causing greater differences between market information and earnings information. Two, changes in the overall sample composition. Specifically, a reduction in brick and mortar type observations (where capital costs are not recognized at purchase) relative to an increase in high tech and research intensive firms (where investments in research and development are immediately expensed). Such a change in composition would account for positive returns when earnings are negative, since research and development costs are expensed (reducing earnings), but are generally seen as investments by the market; whereas, fixed asset investment costs are deferred on the income statement through depreciation. I invite future research to investigate and to test whether my conjecture holds true.

To examine the effect on observations with a BTM greater than one and losses, I restrict the sample to only loss observations and include an indicator variable, BTMIND (models $2 \mathrm{a}$ and $2 \mathrm{~b}$ ), which is equal to 1 if the observation's BTM ratio is greater than one and also the interaction between BTMIND and earnings $(X)$. Of the 40,337 negative observations, 12,402 have a BTM greater than one, approximately 1 in 3, which is higher than the general population (of about 1 in 4). The coefficient on earnings $\left(\beta_{l}\right)$ is negative $-0.29(p<0.01)$, indicating that firms with negative earnings and a BTM less than one have increasing returns, consistent with the general sample. The coefficient on the interaction between earnings and BTMIND is positive, indicating that it is significantly different from observations with a BTM less than one $(0.13, p<0.01)$, consistent with investors not interpreting these negative earnings as investments. Instead, as predicted, the positive coefficient is consistent with the hypothesis that investors consider the losses to be more persistent when the likelihood of using the adaptation option is lower. As also predicted, the information content $\left(R^{2}\right)$ is much higher when bifurcating the sample between BTM greater than or less than one, increasing from 0.1 to 4.4 percent (Note 5).

Results using the change in earnings (panel B) are largely of the same tenor as found in panel A, although the coefficient on $\beta_{I}$ with the loss only sample is positive. The profit only sample has a coefficient of 2.62 and an $R^{2}$ of 6.9 percent. Using the loss sample (67,117 observations), the coefficient is 0.35 , much smaller than the full sample $(0.81)$ and the positive only sample. The $R^{2}$ follows the expected pattern of smallest for the losses sample and largest for the profits sample.

Of the 67,117 negative observations in the earnings-change specification, 19,464 have a BTM greater than one (19 percent). Analyzing model $2 \mathrm{~b}$, that includes the interaction between BTMIND and the change in earnings, one sees that the coefficient on the interaction is positive as hypothesized (0.14). Similar to the levels regression, the $R^{2}$ is also higher, going from 0.1 percent without the interaction to 3.8 percent with the interaction. The coefficient on the indicator variable $\left(\beta_{2}\right)$ is negative in both the levels and changes specifications as expected (untabulated).

Overall, the results support the hypothesis that the ERC on observations with losses and a BTM greater than one is larger than observations with losses and a BTM less than one. Also, the $R^{2}$ is higher when bifurcating on whether the BTM ratio is greater than one or not. In addition to my main findings, I find some evidence consistent with a change in the overall relation between the ERC and returns. Specifically, that under the levels specification, returns appear to be increasing in negative earnings - possibly due to increased conservatism. 


\section{Conclusion}

This paper serves to combine prior literature on the adaptation option (see Berger et al, 1996 and Burgstahler and Dichev, 1997), ERC attenuation (Lev, 1989 and Hayn, 1995), and the BTM ratio (Oler, 2011). More precise, this paper investigates the relation between earnings information, the adaptation option, and firm value. Prior research shows that stock prices impound earnings information to a lesser degree when earnings are negative because there is a higher expectation that the adaptation option will be used. Extending this theory, I hypothesize that if there is a higher likelihood that the firm will not utilize the adaptation option, then the negative earnings will continue to be impounded into price.

Empirically, I test the hypothesis by regressing earnings on returns and partition the sample into positive and negative earnings as well as BTM greater than or less than one subsamples. The partitioning on the BTM ratio is to proxy for firms that are less likely to utilize the adaptation option, given that one is the theoretical point of adaptation. My results are consistent with my hypothesis. Namely, that both the ERC and the $R^{2}$ are higher for the loss subsample when partitioned on BTM ratios greater than one.

Results also suggest that the properties of the relation between earnings and returns may be changing over time. I find that, at least under the levels specification, the market interprets negative earnings as positive investments. I conjecture that this is due to an increase in conservatism over time as well as an increase in the number of firms performing research and development activities, but leave empirical testing to future research.

\section{References}

Ball, R. \& Brown, P. (1968). An empirical evaluation of accounting income number. Journal of Accounting Research, 6,159-178. http://dx.doi.org/10.2307/2490232

Beaver, W. (1968). The information content of annual earnings announcements, Journal of Accounting Research,6, Supplement, 67-92. http://dx.doi.org/10.2307/2490070

Berger, P.,Ofek, E., \& Swary, I. (1996). Investor Valuation and Abandonment Option. Journal of Financial Economics, 42,257-87. http://dx.doi.org/10.1016/0304-405X(96)00877-X

Bernard, V. \& Thomas, J. (1990). Evidence that stock prices do not fully reflect the implications of current earnings for future earnings. Journal of Accounting and Economics, 13, 305 - 340. http://dx.doi.org/10.1016/0165-4101(90)90008-R

Burgstahler, D. \& Dichev, I. (1997). Earnings, Adaption, and Equity Value. The Accounting Review, 72, 187 - 215.

Collins, D. \& Kothari, S.P. (1989). An analysis of international and cross-sectional determinants of earnings response coefficients. Journal of Accounting and Economic, 11, 143-181. http://dx.doi.org/10.1016/0165-4101(89)90004-9

Collins, D., Kothari, S.P., Shanken, J., \& Sloan, R. (1994). Lack of timeliness and noise as explanations for the low contemporaneous returns-earnings association. Journal of Accounting and Economics 19, 289-324. http://dx.doi.org/10.1016/0165-4101(94)90024-8

Danielson, M., \& Press, E. (2003). Accounting Returns Revisited: Evidence of their Usefulness in Estimating Economic Returns. Review of Accounting Studies, 8, 493 - 530. http://dx.doi.org/10.1023/A:1027368116754

Freeman, R., \& Tse, S. (1992). A Nonlinear Model of Security Price Responses to Unexpected Earnings. Journal of Accounting Research, 30, 185 - 209.http://dx.doi.org/10.2307/2491123

Givoly, D. \& Hayn, C. (2000). The Changing Time-Series Properties of Earnings, Cash Flows and Accruals: Has Financial Reporting Become More Conservative?" Journal of Accounting and Economics, 29, 287-320. http://dx.doi.org/10.1016/S0165-4101(00)00024-0

Hayn, C. (1995). The Information Content of Losses, Journal of Accounting and Economics, 20, 125 - 153. http://dx.doi.org/10.1016/0165-4101(95)00397-2

Kormendi, R. \& Lipe, R. (1987). Earnings innovations, earnings persistence, and stock returns. Journal of Business 60, 323-345. http://dx.doi.org/10.1086/296400

Kothari, S. P. (2001). Capital markets research in accounting. Journal of Accounting and Economics, 31, 105-231. http://dx.doi.org/10.1016/S0165-4101(01)00030-1

Kothari, S.P. \& Sloan, R. (1992). Information in prices about future earnings. Journal of Accounting and Economics, 15, 143 - 171. http://dx.doi.org/10.1016/0165-4101(92)90016-U

Lev, B., (1989). On the usefulness of earnings and earnings research: Lessons and directions from two decades of 
empirical research. Journal of Accounting Research, 27, 153-192. http://dx.doi.org/10.2307/2491070

Oler, M. (2011). Non-Conservative Accounting and the Adaptation Option: Determinants and Implications of Firms that Continue with a Book-to-Market Ratio Above One. Working Paper, Virginia Tech University.

Ramakrishnan, R. \& Thomas, J. (1998). Valuation of Permanent, Transitory, and Price-irrelevant Components of Reported Earnings. Journal of Accounting, Auditing and Finance, 13, 301-336.

White, H. (1980). A heteroskedasticity-consistent covariance matrix estimator and a direct test for heteroskedasticity. Econometrica, 48, 817-838. http://dx.doi.org/10.2307/1912934

\section{Notes}

Note 1. All $R^{2}$ 's are adjusted.

Note 2. I use heteroskedastic consistent standard errors (White, 1980).

Note 3. All of the coefficients are significant at the less than 1 percent level.

Note 4. Like Hayn, under the earnings-change specification for loss cases, I include profitable cases in which a loss is reported in the previous year, and for profitable cases, I exclude cases in which a loss is reported in the previous year.

Note 5. Similar to Hayn (1995), I am unable to perform a test of significance on the $R^{2}$ since my samples are non-nested.

Table 1. Descriptive Statistics

\begin{tabular}{|l|r|r|r|r|}
\hline & \multicolumn{2}{|c|}{ Whole Sample } & \multicolumn{2}{c|}{ BTM > 1 Sample } \\
\hline Variable & \multicolumn{1}{|c|}{ Mean } & \multicolumn{1}{c|}{ Median } & \multicolumn{1}{c|}{ Mean } & \multicolumn{1}{c|}{ Median } \\
\hline Total assets $(\$ 000,000)$ & $\$ 4,076$ & $\$ 136$ & $\$ 2,234$ & $\$ 100$ \\
\hline Sales $(\$ 000,000)$ & 1,405 & 104 & 653 & 0.48 \\
\hline Earnings per share $(\$)$ & 0.99 & 0.65 & 0.70 & 0.03 \\
\hline Returns & 0.14 & 0.12 & 0.11 & 1.36 \\
\hline BTM & 0.81 & 0.62 & 1.56 & \\
\hline Negative observations & $40,337^{*}$ & & $12,634^{*}$ & 44,089 \\
\hline Positive observations & 125,541 & & 31,236 & \\
\hline N & & 166,709 & & \\
\hline
\end{tabular}

The above table contains the descriptive statistics on the whole sample as well as the sub-sample of observations with a BTM greater than one. Earnings per share are before extraordinary items. Returns are accumulated over a 12 month period starting eight months before fiscal year end.

* There are 831 observations with earnings equal to 0 in the all observations sample and 219 in the BTM greater than 1 observations sample. 
Table 2.

Panel A: Levels regressions

$$
\begin{aligned}
& { }^{1 \mathrm{a}} R_{i t}=\alpha+\beta_{1} \frac{X_{i t}}{P_{i t-1}}+\varepsilon_{i t} \\
& { }^{2 \mathrm{a}} R_{i t}=\alpha+\beta_{1} \frac{X_{i t}}{P_{i t-1}}++\beta_{2} B T M I N D^{i t}+\beta_{3} \frac{X_{i t}}{P_{i t-1}} \times \text { BTMIND }^{i t}+\varepsilon_{i t}
\end{aligned}
$$

\begin{tabular}{|c|c|c|c|c|}
\hline Variable & Observations & $\beta_{1}$ & $\beta_{3}$ & Adjusted $R^{2}$ \\
\hline All cases $(1 a)$ & 166,709 & $0.58 * * *$ & - & $3.8 \%$ \\
\hline Profit cases (1a) & 125,541 & $2.00 * * *$ & - & 9.9 \\
\hline Loss cases (1a) & 40,337 & $-0.19 * * *$ & - & 0.1 \\
\hline Loss only observations with indicator & 40,337 & $-0.29 * * *$ & $0.13 * * *$ & 4.4 \\
\hline
\end{tabular}

interaction (2a)

Panel B: Changes regressions

$$
\begin{aligned}
& { }^{1 \mathrm{~b} R_{i t}}=\alpha+\beta_{1} \frac{\Delta X_{i t}}{P_{i t-1}}+\varepsilon_{i t} \\
& { }^{2 \mathrm{~b}} R_{i t}=\alpha+\beta_{1} \frac{\Delta X_{i t}}{P_{i t-1}}++\beta_{2} B T M I N D^{i t}+\beta_{3} \frac{\Delta X_{i t}}{P_{i t-1}} \times B_{T M I N D^{i t}+\varepsilon_{i t}}
\end{aligned}
$$

\begin{tabular}{lclcl}
\hline Variable & Observations & $\boldsymbol{\beta}_{1}$ & $\boldsymbol{\beta}_{3}$ & Adjusted $\boldsymbol{R}^{2}$ \\
\hline All cases $(1 b)$ & 152,482 & $\mathbf{0 . 8 1} * * *$ & - & $\mathbf{5 . 6 \%}$ \\
Profit cases $(1 b)$ & 86,132 & $\mathbf{2 . 6 2} * * *$ & - & $\mathbf{6 . 9}$ \\
Loss cases $(1 b)$ & 67,117 & $\mathbf{0 . 3 5} * * *$ & - & $\mathbf{0 . 1}$ \\
Loss only observations with & 67,117 & $\mathbf{0 . 1 8} * * *$ & $\mathbf{0 . 1 4} \mathbf{4}^{* * *}$ & $\mathbf{3 . 8}$
\end{tabular}
indicator interaction (2b)

The above tables contain my main results. Panel A contains the results using a levels specification. Panel B contains a changes specification where $\Delta X$ is the change in earnings from prior year. BTMIND is an indicator variable equal to 1 if the observation has a BTM ratio greater than one. $* * *$ indicates that the coefficient is significant at the greater than 1 percent level. 831 (219) observations do not appear in the positive or negative (change) samples because earnings are 0 .

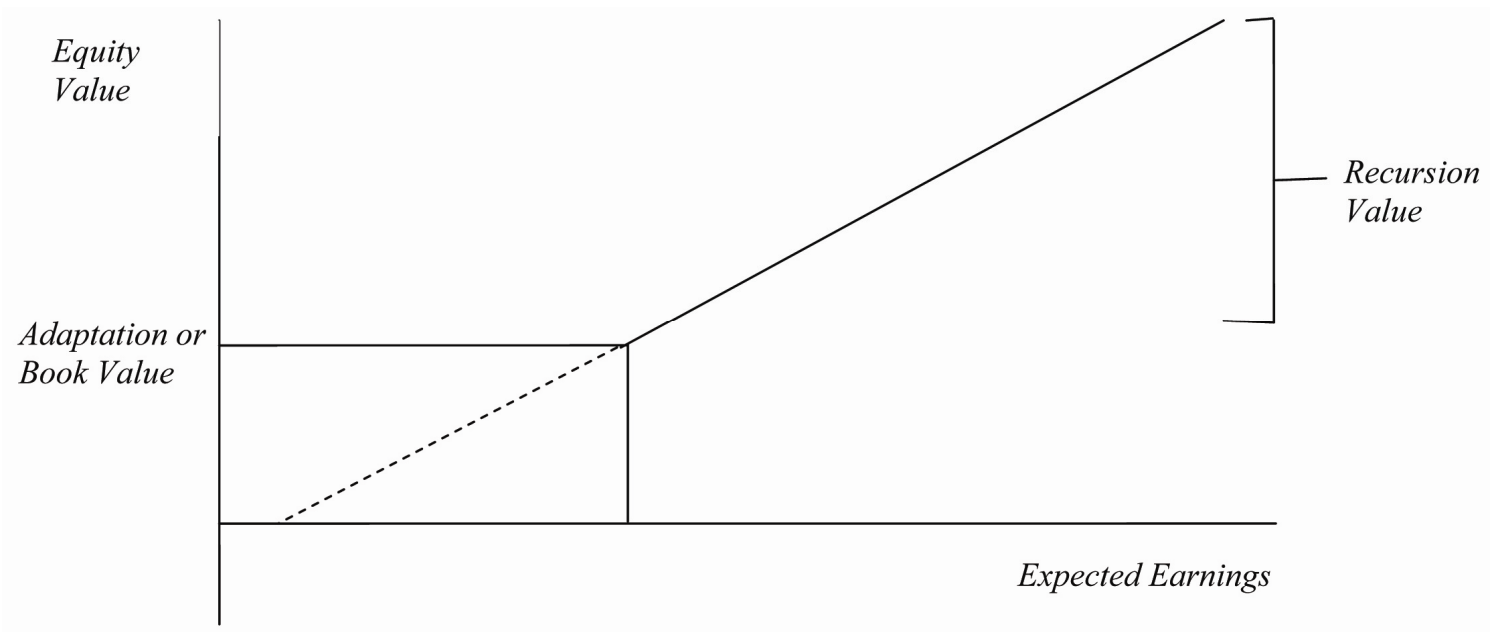

Figure 1.

The figure above illustrates the relationship between the recursion value, adaptation or book value, and the value of the firm (see Burgstahler and Dichev, 1997). The dashed portion of the recursion value line represents value from the current use of the assets that is below the adaptation strike price. 